\title{
MENSTRUAL REGULATION AS A MEANS OF REPRODUCTIVE CONTROL: THE LAW'S RESPONSE TO DISABLED BODIES AND MENSTRUATION
}

\section{MARIA NI FHLATHARTA*}

Every day, millions of people make decisions about menstruation. They make decisions about what sanitary products to use, about pain relief, about with whom they will discuss their experience of menstruation. They make decisions about contraception to induce amenorrhea. These decisions may be influenced by family, poverty, society, and culture, but they remain, for the most part, up to the individual. However, this right to autonomy is not extended to all people equally. Some disabled people, for example, have these decisions made by substituted decision makers, including the courts. ${ }^{1}$ This is in violation of their rights; nevertheless, this practice continues in various jurisdictions, including through guardianship and conservatorship laws.

Legal capacity is a concept that refers to both an individual's legal personhood and to their legal agency, or power to act. Legal capacity is most closely associated with Article 12 of the United Nations Convention on the Rights of Persons with Disabilities (CRPD). The right previously existed in Article 15 of the Convention on the Elimination of All Forms of Discrimination Against Women, as well as in the Universal Declaration of Human Rights ${ }^{2}$ and the International Covenant on Civil and Political Rights. ${ }^{3}$ Article 12 did not restate legal capacity as a right; rather, it clearly extended the right to persons with disabilities. Disabled people are the group most commonly deprived of their legal capacity. ${ }^{4}$

\footnotetext{
* Maria Ní Fhlatharta holds an LLM from NUI Galway. She is a research assistant on the Re(al). Productive Justice Project at the Centre for Disability Law and Policy. Her research intrests include abortion, legal capacity, access to justice and human rights in healthcare.

${ }^{1}$ Linda Steele \& Beth Goldblatt, The Human Rights of Women and Girls with Disabilities: Sterilization and Other Coercive Responses to Menstruation, in The Palgrave HandBook of Critical Menstruation STUDIES 77, 82 (2020) https://link.springer.com/chapter/10.1007\%2F978-981-15-0614-7_8.

${ }^{2}$ G.A. Res. 217A (III), Universal Declaration of Human Rights, art. 7 (Dec. 10, 1948).

${ }^{3}$ G.A. Res. 2200A (XXI), International Covenant on Civil and Political Rights, art. 26 (Dec. 16, 1966).

${ }^{4}$ Comm. on the Rights of Persons with Disabilities, General Comment No 1 (2014), U.N. Doc. $\mathrm{CRPD} / \mathrm{C} / \mathrm{GC} / 1$ (Apr. 11, 2011).
} 
Under Article 12 of the CRPD, perceived or actual deficits in mental capacity must not be used as an excuse to deny legal capacity. Such practices must be abolished in order to ensure that full legal capacity is recognised on an equal basis with others. The Committee on the Rights of Persons with Disabilities (the "Committee") understands that some persons will require support in making decisions, but that support must respect the rights, wills, and preferences of persons with disabilities and should never amount to substituted decisionmaking. ${ }^{5}$ Substituted decisionmaking takes multiple forms, including plenary guardianship, conservatorship, and partial guardianship. Medical decisions and decisions around menstruation are made under such substituted decisionmaking regimes, as required by the CRPD. The Committee has noted that certain jurisdictions also have higher rates of imposing substitute decision-makers on women. ${ }^{6}$ Instead, they should be made using a supported decisionmaking framework based on an individual's will and preferences. This is a departure from traditional systems, in which states used discriminatory concepts, such as mental capacity, to implement substituted decisionmaking regimes such as guardianship, depriving people of their legal capacity.

Where, after all efforts to support a person in making a decision have been taken, it is not practicable to determine the will and preferences of an individual, the "best interpretation of [their] will and preferences" will be used to make the decision. ${ }^{7}$ The Committee makes clear that making decisions under the "best interest" framework is a violation of Article 12. Only three states have made significant reforms to bring their law in line with Article $12 .^{8}$

Decisions about menstruation are frequently made by third parties under substituted decisionmaking frameworks. While some states impose greater restrictions ${ }^{9}$ in cases that impact the disabled person's fertility in the long term (such as sterilisation), others use the same framework under which all substituted decisions are made.

In order to illustrate the violations faced by menstruating persons with disabilities, this Article will discuss two cases from the England and Wales Court of Protection: The
${ }^{5} I d$.
${ }^{6} I d$.
${ }^{7} I d$.
${ }^{8}$ These states are Columbia, Peru, and Costa Rica.
${ }^{9}$ That is, decisions must be made by courts rather than by a guardian or a committee. 
Local Authority v HP \& Ors ${ }^{10}$ and University Hospitals of Derby and Burton NHS Foundation Trust $v J{ }^{11}$ Both cases involved young women with intellectual disabilities, and both were decided under a "best interest" framework.

The earlier case, $H P$, concerned a nineteen-year-old woman with what was identified as a mild learning disability and "challenging behaviour." ${ }^{12}$ HP lived in a residential facility under the direction of the local authority. This case concerned a number of orders relating to the young woman, including her capacity to consent to sex, place of residence, treatment plan, family contact, and menstrual management.

HP had already been receiving the Depo-Provera contraception injection per earlier interim declarations made by the Court of Protection. The issue under consideration was whether it would be in HP's best interest to continue on Depo-Provera as a course of treatment. Uncontested medical evidence was put forward that the Depo-Provera injection was the best way of providing contraception for HP. It was stated that there was a small risk that HP would engage in sex at a point where she did not have the capacity to consent. ${ }^{13}$ The small risk of pregnancy would not by itself satisfy the best interest criteria, but in combination with a therapeutic effect, it might meet the best interest threshold. The therapeutic effects of Depo-Provera were a potential reduction in menstrual bleeding and induction of amenorrhea in up to fifty percent of cases. It was also stated that the use of Depo-Provera injections was the accepted practice for women with learning difficulties. ${ }^{14}$

The court heard that HP had experienced difficulties with hygiene and managing sanitary protection, including that she had smeared menstrual blood on herself and on the walls. It was not contested that HP suffered significant physical pain and discomfort with her period, which was not the case while she was receiving Depo-Provera. The judge inferred from her behaviour that she found the experience of menstrual bleeding distressing. The judge held that the combination of reducing menstruation along with the contraceptive effect were sufficient to justify this medical treatment. In many respects, this is no different from other medical decisions, except that it would impact more than

\footnotetext{
${ }^{10}$ The Local Auth. v HP \& Ors [2013] EWCOP B40 (Eng.).

${ }^{11}$ Univ. Hosps. of Derby \& Burton NHS Trust Found. v J [2019] EWCOP 16 (Eng.).

${ }^{12}$ The Local Auth. v HP \& Ors [2013] EWCOP B40 (Eng.).

${ }^{13} I d$. It was established earlier in the judgment that her capacity to consent fluctuated.

${ }^{14} I d$. It was unclear what the basis for this statement was and whether it was referring to administration without consent.
} 
HP's mind and body. It would remove her ability to concieve for a significant period of time, as resumption of normal ovulation or fertility following cessation of use of DepoProvera can take up to one year. ${ }^{15}$

The second case for consideration is University Hospitals of Derby and Burton NHS Foundation Trust $v$, another Court of Protection case. This case concerned Anne, a woman with a diagnosis of autistic spectrum disorder and a severe learning disability. She was also described as having challenging behaviour, which was exacerbated by her menstrual cycle. She was distressed at the sight of menstrual blood. She had endometriosis and her periods were painful. Her doctors tried a number of contraceptives to supress menstruation and settled on a hormonal medication Decapeptyl, which, while licenced for six months, Anne had been taking for much longer. Anne had long been afraid of leaving the house and had done so only in medical emergencies. She also feared road transport. It was proposed that she undergo a complete hysterectomy, which was agreed upon by Anne's family, medical team, disability support team, and the Official Solicitor.

The Official Solicitor, in recommending the hysterectomy, stated that Anne herself was unable to express a clear view about the operation, but had indicated that she did not want to have menstrual bleeding or a child. It was put forward that the surgery was a "necessary and proportionate interference with her rights." The court ordered the surgery using sedation and other measures of deception in order to get Anne to the hospital.

Interestingly, there is no way of telling whether either woman in either case would have rejected their proposed course of treatment. If a will and preferences framework had been applied by the courts, or allowed for other methods of supported decision making, both women may have chosen to stop their periods, given that they found them so distressing. These were decisions that could have been made with support. There was no option but to use substituted decision making in both of these cases. A supported decision making framework would center these women's voices, rather than using a legal framework which robs them of dignity, autonomy, and voice. Neither woman was heard in their individual cases, and decisions were on the basis of their best interests.

\footnotetext{
${ }^{15}$ Pfizer Limited, Depo-Provera $150 \mathrm{mg} / \mathrm{ml}$ Injection Sterile Suspension for Injection, ELEC. MEDS. COMPENDIUM, https://www.medicines.org.uk/emc/product/6721/smpc [https://perma.cc/WCX5-ZEQV].
} 